\title{
Medical Tourism and Inclusive Growth: Significance of Ayurveda Sector
}

\author{
Jacob John* and Seema Chelat ${ }^{\dagger}$
}

\begin{abstract}
Medical tourism has emerged as a critical component of tourism in India. Medical tourism, a subset of health tourism, is an emerging segment of tourism industry and there are only a few serious studies conducted on the topic. With the growing importance of medical tourism and the thrust given by central and state governments to promote tourism, the paper explores the potential role of Ayurveda in medical tourism sector. A survey of practitioners, manufacturers, researchers, representatives of various associations in Ayurveda sector was carried out and the findings of the survey, which have policy implications, have been used to explore the possibilities of promoting Ayurveda sector in the medical tourism with the participation of local government institutions and community in order to achieve inclusive growth. The dominance of small and medium enterprises, individual researchers and practitioners, and labour intensive operations in Ayurveda based medical tourism and its impact on inclusive growth is highlighted. The paper also aims to formulate an action plan to address the critical issues of Ayurveda sector to enable it to play a central role in medical tourism.
\end{abstract}

Keywords: Ayurveda, Community, Devolution, Local Government and Medical tourism

\footnotetext{
* Director, Kerala Development Society (KDS), New Delhi 110058; jacob305@rediffmail.com

† Research Officer, KDS New Delhi 110058; seemachelat@gmail.com
} 


\section{Introduction}

In India, tourism sector has gone through many developmental phases and currently tourism industry is reckoned as a major instrument for social integration and economic development. Under this sector, health tourism has a focus on good health, general wellbeing and its pursuit has a significant position. It may be noted that health tourism is a broader term as medical tourism can be termed as a subset of health tourism. Ayurveda is generally viewed as a treatment for relaxation of mind and body and for overall wellbeing. Even though it has the potential and treatment system for almost all diseases, lack of awareness and information prevent people from availing those benefits. In this paper, we focus on this unexplored aspect of Ayurveda. With the growing importance of medical tourism and the thrust given by central and state governments to promote tourism, the paper explores the potential role of Ayurveda in medical tourism sector. Medical tourism encompasses the act of travelling to other nations to obtain various treatments such as medical, dental and surgical care. Ayurveda has a huge untapped potential in this era of life style diseases and concerted effort is required to establish Ayurveda in this domain. The objectives of the paper are to critically examine the key issues and challenges faced by medical tourism sector in view of the recent criticism and the prospects of Ayurveda in this domain. The paper aims to formulate an action plan to address the critical issues of Ayurveda sector for evolving as an alternative medical care system and to provide a central role to Ayurveda in medical tourism for achieving inclusive growth. The paper comprises of four parts. The first part is the review of literature and the second part is devoted to the potentials of Ayurveda as a viable option for medical tourism and inclusive growth. The third part of the paper examines the role of local government institutions-Panchayati Raj Institutions and Municipalities, along with communities by taking Kerala as a case study in medical tourism while the fourth section suggests an action plan for the promotion of Ayurveda as a medical tourism sector for achieving inclusive growth. 


\section{Review of Literature}

Tourism sector has emerged as one of the devices of economic development, poverty alleviation, employment generation and sustainable human development. Tourism has become the second largest net foreign exchange earner for the country. "Tourism Sector is a major generator of employment. As a highly labour intensive activity, tourism and tourism support activities create a high proportion of employment and career opportunities for low skilled and semi-skilled workers, particularly for poor, female and young workers. Women make up 70 percent of the labour force in tourism sector and half of all tourism workers are 25 years or under. The tourism sector can be an important source of employment for many of the unemployed youth and consequently reduces the poverty in the society" (UNCTAD, 2010).

There are a few studies which discuss the differences between health tourism and medical tourism. Carrera and Bridges (2006) and Connell (2006) have identified 'health tourism' with general health and wellbeing, while in 'medical tourism', tourism is combined with medical, surgical or dental intervention to improve or restore health in the long term. International trade in medical services has vast economic potentials in developing countries. Medical tourism is not a universally feasible growth strategy as it is successful only in countries with economic and political advantages that enable them to navigate around international and domestic obstacles to trade in medical services. For a successful medical tourism industry, when coupled with private and public partners, it may lead to public health improvements in developing countries (Bookman 2007).

The scope of expanding medical tourism has been increasing due to certain reasons related price and wages. 'Emerging' nations have far lower costs of living compared to western countries, because of which wages are far lower. On the other hand they have all the modern facilities which are as good as any western countries along with educated medical professionals who can offer medical procedures for less than half the price Rollyson (2010). 
Medical tourism has emerged as a critical component of tourism in India. Through its National Health Policy of 2002, India is promoting medical tourism in various means. The policy states that 'to capitalize on the comparative cost advantage enjoyed by domestic health facilities in the secondary and tertiary sector, the policy will encourage the supply of services to patients of foreign origin on payment. The rendering of such services on payment in foreign exchange will be treated as 'deemed exports' and will be made eligible for all fiscal incentives extended to export earnings'. This growth in private health sector was part of a conscious government policy effort that chose to promote these components of health care. The government took a series of measures to make privatized health care sectors prosper. These steps include extending subsidies in terms of cheap land, concessions for the import of equipments and drugs, placing private institutions on government panels and making them a part of government insurance schemes. The government has also provided trained doctors and expert physicians to the private sectors through subsidized state-supported medical education (Reddy \& Quadeer, 2010).

Though medical tourism is an emerging segment of tourism industry, there are only a few serious studies done on the topic. The available literature mainly deals with the concerns about the thoughtless promotion of medical tourism and its after effects on domestic neighbourhood. Medical tourism caters to the treatment of the rich and hence the service of these private hospitals do not promote the objectives of the nation at large and most of the times they do not accord the priorities of the locals. Only the upper crust gains through medical tourism and this is because of the skewed priority in this service structure. Medical tourism may not have any significant breakthrough in the domestic medical care treatments or for the prevention of prevalence of major diseases in the country because of this skewed policy. The country continues to be undernourished and there is high prevalence of communicable disease and maternal and infant mortality. Unregulated privatization and medical tourism in fact create distortions and have negative implications for public health (Reddy \& Quadeer, 2010). 
Choudhury and Dutta (2004) argue in their paper that in its effort to fill its coffers with foreign exchange through medical tourism, the government has underplayed the obvious contradiction between a vast uncared majority and an over cared rich minority and there was an unethical focus on profits through medical tourism. By ignoring many of the fundamental negative implications of medical tourism, the government started promoting policies such as shift of subsidies to the private sector, extremely low spending in public sector healthcare, etc. Medical tourism can be termed as a gamble for quick money while the market exists. It helps to fill private pockets. But there is no evidence to show that the money earned through such practices is transferred to the larger public healthcare systems or shared. The so called low cost of these services is at the expense of public health care system and the private players make huge profits (Qureshi, 2001).

In the heavily dualistic system of healthcare existing in India with inadequate and inefficient public health services on the one hand and a corporatized medical system using high-end medical technology and state-of-the-art infrastructure on the other, the promotion of medical tourism will accentuate the divide between the haves and the have-nots in healthcare. (Godwin, 2004).

There are several other issues associated with medical tourism and inclusive growth remains elusive and unaddressed in the existing literature. The limited number of studies reviewed showed different adverse results of medical tourism and a serious research based study has not come out in respect of strategies and steps to make the growth in medical tourism an inclusive one. This paper is an attempt to explore the possibilities of promoting Ayurveda sector in the medical tourism sector with the participation of local government institutions and community to achieve inclusive growth. By promoting Ayurveda, most of the issues raised in literature surveys can be addressed.

\section{Ayurveda and Medical Tourism: Scope and Issues}

Medical tourism in the field of allopathic/modern medicine has evoked several adverse remarks in respect to its failure in 
providing healthcare services for the poor and achieving inclusiveness in healthcare sector. Recently, the government has been criticized for extending incentives and support for the promotion of medical tourism by subsidizing the rich coming from the developed countries. Government has been sacrificing the public health sectors, particularly in terms of access, by poor and marginalized population in rural and urban sectors to public health care system, in favour of foreign medical tourists to earn foreign exchange. It is a fact that government resources are needed for medical tourism. While there is a trade-off between welfare and economic growth, there are several evidences to substantiate the fact that government funds are diverted to provide subsidies to rich. Most of the multispecialty hospitals are built on subsidized government land and these institutions are supposed to provide medical care for poor and weaker section of the population. But these funds are diverted for the treatment for the rich tourists from the developed world. Indian medical tourism faces some other issues such as surrogacy, medical waste, etc. Surrogacy is promoted by hospitals as an option for the couples from foreign countries who cannot afford the expensive infertility treatment of their home country. Unfortunately, the Government does not address the problems of, both physical as well as emotional, these poor surrogate mothers. The other biggest issue is the safe disposal of medical waste created out of this tourism.

In this context, it is significant to understand that India has many traditional systems of medicine like Ayurveda, Yoga, Naturopathy Unani Panchakarma, Rejuvenation Therapy, etc. which are among the most ancient and very popular systems of medical treatment. This sector can be developed as an alternative medical care system for medical tourism. India's affordable, cost-effective and efficient medical service in this sector can make it a favourable destination for healthcare for many international tourists.

India has abundant talent in this sector which can be utilized for promoting tourism and can provide medical care of international standard at a comparatively low cost. In this traditional sector India faces fewer challenges as these practices belong to its traditional form of treatments. At the landmark Alma Ata ('Health for All by 2000') Declaration of 1978, the World Health 
Organisation has identified the significant role of indigenous/traditional medicine. Low cost and accessibility made traditional medicine an ideal alternative for the healthcare delivery programmes. But it was left to the concerned individual government machinery to make it more viable and integrate it to the main stream modern medicine.

In the last two decades, there has been a growing demand for Ayurvedic treatment and medicines in India as well as outside India. Let us discuss the potentials of Ayurveda sector in the context of the state of Kerala. Ayurveda registered 10-12 per cent growth yearly and contributed around three percent value addition annually to the manufacturing sector in Kerala (Madhavan, 2009). Driven by demand both from within and outside the country for Ayurvedic products and treatments, there was modernization and innovation in this sector. At the same time, a parallel niche market for traditional Ayurvedic care depending on its legacy is also serving the public at large. (Madhavan, 2011)

For a long time Ayurvedic treatments were used as an alternative medical care system. But the recent surge in this sector shows the curiosity of man searching for an answer in indigenous or traditional systems of medicine due to the disillusionment with established treatment propositions of allopathic medicine. It becomes clearer that throughout the world, indigenous medical systems are becoming part of mainstream healthcare system. Different medical traditions do exists in different parts of the world and India is one of those few countries that have a well-established traditional medical care. India occupies a unique position due to its centuries-old indigenous medical systems along with the strong presence of modern bio-medicine and has broken a new ground in such a medical revolution.

Kerala, the state with a huge potential, has made certain achievements in developing medical tourism. Through systematic production of medicine, institutionalization of education and professionalization of clinical practice, Kerala Ayurveda sector has made some progress during the past two decades. By promoting Ayurveda, the state has achieved about 30 per cent increase in 
tourist flow that are availing the Ayurvedic medical care with 40 per cent increase in tourism revenue of the state. With an objective of ensuring quality in service and hygiene, Kerala tourism has introduced the "Green Leaf" and "Olive Leaf" grading for Ayurvedic institutions."Green Leaf is given to those Ayurvedic centres which provide 'five star' facilities while Olive Leaf is for the 'three star' category. These classifications are meant to give credibility of service providers and to ensure the quality to the clients. In addition, many measures have been taken by the department to enhance safety and quality through the introduction of quality standards, registration, certification, regulation and legislation. Despite these measures, comprehensive interventions such as guidelines and measures to ensure fair pricing are still missing.

Some of the issues of allopathic medical treatment system under medical tourism can be addressed by promoting Ayurveda ${ }^{1}$. The treatment methodologies followed in this indigenous medical care system are different. The waste material generated are to some extend is bio degradable and can be easily disposed off. Major chunk of the land subsidy and public health fund allocation have gone into allopathic medical care system and the question of fund diversion is minimal if Ayurveda as alternative medical care system is opted. Ethical issues like surrogacy can be addressed effectively by promoting Ayurveda, an Indian traditional medical practice. Moreover, the participation of the local community is quite feasible and effective in Ayurveda, the traditional system of medicine.

\section{A Scenario of Administration of Ayurvedic Sections in Kerala}

In India, after the 73rd and 74th constitutional amendment, decentralization of power has become an integral part of governance system in India in general and Kerala in particular. With the decentralization of powers to local self-governing institutions, local administration started to play an important role in the formulation and implementation of development works at the grass root level in Kerala. A three-tier Panchayat Raj Institution in rural areas and municipalities in urban areas were set up to carry out all the development and social plans and schemes in a well 
thought out manner. The decentralized system of governance provides maximum opportunity for community participatory governance and decision making by all sections of the society.

Kerala has a strong Panchayati Raj system with a total of 1165 Panchayati Raj Institutions that consist of 999 Gram Panchayats, 152 Block Panchayats and 14 District Panchayats. Subsequent to the enactment of the Panchayati Raj Act various Public Health Institutions were transferred to the three-tier Panchayats in Kerala in February 1996. Kerala has a total of 2706 Public Health Institutions that comprises of 1272 Allopathic, 864 Ayurvedic and 570 Homeopathic Institutions. Functionaries/ personnel of Public Health Institutions are not yet transferred to Panchayati Raj Institutions. Doctors and other officials of Ayurvedic institutions are still under the Indian System of Medicine Department of government of Kerala. Regular employees of Public Health Institutions continue as state government employees under respective departments. Panchayati Raj Institutions are given a certain level of control over these functionaries/ personnel. However, their controls and responsibilities are limited. Their salary is paid by the Department of Indian System of Medicine, Government of Kerala. They are responsible for recruitment, placement and promotion of health personnel and Panchayati Raj Institutions do not have any role in these activities. However, Government of Kerala has given managerial and part disciplinary control over the staff of public health institutions to the concerned local government institutions. It is significant to note that local government institutions and health personnel hold joint responsibilities and they share certain responsibilities. Local government institutions have the full responsibility for building, upgrading and maintaining infrastructure. Both local government institutions and health officials involve in the supply of drugs while the latter is responsible for the supply of major share of drugs. It is significant to note that both local government institutions and officials of public health institutions have disciplinary control over health staff. This situation has resulted in dual responsibilities and controls system. Hospital Management Committee is a common platform for local government institutions 
and health officials. It is a democratically constituted body that provides a platform for elected representatives and officials of Panchayati Raj Institution and health officials to work jointly for the efficient functioning of Public Health Institutions. Each Ayurvedic hospital or dispensary has a Hospital Management Committee $^{2}$ (HMC). The system of dual controls and responsibilities yielded good results when elected representatives and officials of local government institutions and medical officers were in good terms and maintained positive and cordial relationships. There is a substantial improvement in respect of attendance of health officials, availability of medicines, quality of services and quality of infrastructure due to the intervention of PRIs in 2012 compared to 2005 (John, 2012).

Kerala has made the distribution of public health and sanitation functions among three tiers of PRIs. Gram Panchayats are given dispensaries, primary health centres and sub centers, maternity and child welfare centres, immunization and other preventive measures, family welfare programme and sanitation programme. Community health centre and taluk hospitals are placed under block panchayats. Management of district hospitals, setting up of centers for care of special categories of handicapped and mentally disabled people and co-ordination of centrally and state sponsored programmes at district level are given to zilla panchayat. These public health institutions are under Allopathy, Ayurveda and Homeopathy services.

All the Ayurvedic dispensaries and hospitals come under Indian System of Medicine (ISM) Department. The District Medical Officer (ISM) is the coordinating officer under Ayurveda. The transfer of institution under Ayurveda sector to local government institutions is presented in the Table 1. In Ayurveda, District Ayurveda Hospitals, Government Ayurvedic Hospitals, Special Ayurveda Hospitals, Taluk Ayurveda Hospitals and Primary Health centres like Government Ayurveda Dispensaries are transferred to local government institutions. A strong network of Ayurveda hospitals/dispensaries is functioning in all the districts of Kerala. 
Table 1: Ayurveda and Local Government Institutions

\begin{tabular}{|l|l|l|l|}
\hline $\begin{array}{l}\text { System of } \\
\text { Medicine }\end{array}$ & $\begin{array}{l}\text { Public Health } \\
\text { Institutions } \\
\text { transferred to } \\
\text { LGI at district } \\
\text { level }\end{array}$ & $\begin{array}{l}\text { Public Health } \\
\text { Institutions } \\
\text { transferred to } \\
\text { LGI at Taluk/Block } \\
\text { level }\end{array}$ & $\begin{array}{l}\text { Public Health } \\
\text { Institutions } \\
\text { transferred to } \\
\text { LGI at Gram } \\
\text { Panchayat level }\end{array}$ \\
\hline Ayurvedic & $\begin{array}{l}\text { District } \\
\text { Ayurveda } \\
\text { Hospital and } \\
\text { Government } \\
\text { Ayurvedic } \\
\text { Hospital }\end{array}$ & $\begin{array}{l}\text { Special Ayurveda } \\
\text { Hospital and Taluk } \\
\text { Hospital/Government } \\
\text { Ayurveda Hospital }\end{array}$ & $\begin{array}{l}\text { Government } \\
\text { Ayurveda } \\
\text { Dispensaries }\end{array}$ \\
\hline
\end{tabular}

Source: John, Jacob "A Study on Effectiveness of Panchayati Raj Institutions in Health Care System in the State of Kerala" Planning Commission of India

Ayurveda has a strong presence in the state of Kerala. All the Ayurvedic dispensaries and hospitals come under Indian System of Medicine (ISM) Department and the District Medical Officer (ISM) is the coordinating officer under Ayurveda. Public health institutions under Ayurveda consist of district hospital at district level, taluk hospital at taluk level and dispensaries at Gram Panchayat level. Local government institutions and local communities can play a significant role in the development of the Ayurveda sector.

The local government can enforce policies and influence over its communities in a better manner. It is a fact that the local government plays a significant role in the operation and management of public health institutions in the Allopathic sector. In contrast to the Allopathic sector, the scope for community participation under the leadership of local government institutions is quite high in the Ayurveda sector under the context of medical tourism. In the context of sustainable development, they can play very significant roles on the sustenance of its local medical tourism operations and have a strong presence in protecting its resources. Sustainable medical tourism development in the field of Ayurveda should address to the management of all potential resources that meets the needs of both the tourists as well as the local community. The contribution of various stakeholders and the community is 
very crucial in this approach as this include planning and decision making in order to determine the community's long term interest. The local government should consider the community as well as economic needs while making policy decisions and actions as this has the potential for economic growth, employment and increase in the tax base. They can create an environment for medical tourism by raising awareness through various programmes and structured planning so that the benefits should accrue to the local communities. They can adopt area-specific strategies and map best practices to design option appropriate to their specific situations and circumstances.

\section{Ayurveda Sector in Kerala as a Medical Tourism Destination: A Way Forward}

The present study which is quite contemporary in nature depends on field data. The primary data was collected through personal interviews and meetings with various stakeholders using a structured schedule. These include practitioners, manufacturers, researchers, representatives of various associations of Ayurveda sector in Kerala. A total of 100 respondents from the state of Kerala participated in the field survey. The questions were framed to draw data and information to substantiate the major objectives of the study. The schedule covers both qualitative and quantitative data. The qualitative data was based on the observations and experiences of the experts during the course of interviews and meetings. The relevant documents in the related domain were reviewed through a desk study.

The major objective of the survey was to explore the possibilities of promoting Ayurveda sector in the medical tourism sector with the participation of local government institutions and community to achieve inclusive growth. Some of the key issues that emerged need attention of various stake holders. Growing demand for Ayurvedic treatment and medicines remains untapped due to the lack of policy initiatives of various governments including local government. Success of Ayurveda in the treatment of various chronic illnesses is unknown to a significant segment of prospective clients. Lack of quality control system in Ayurveda sector remains unaddressed and moreover, the sector is not yet covered in the 
public health policy. Certain concrete measures are to be taken on a priority basis are given below:

\section{Central and State Governments}

Health is a devolved subject to sub national government and local governments in India. Both central and state governments can take certain initiatives to promote Ayurveda which has been receiving increased attention nationally as well as internationally. The first and foremost step is to ensure regular consultations between various stakeholders in the Ayurveda sector. Academic industry collaboration in Ayurveda sector is quite essential. Given the high prevalence of life style diseases, contributions of Ayurveda and Yoga in addressing these diseases have to be highlighted. Also the contribution of these traditional systems in the field of preventive health care needs to be popularized nationally and globally. Similarly the success of Ayurveda in treatments for various chronic illness including HIV positive cases can also attract clients from various countries. This calls for increased documentation of the innovative findings and its wide dissemination. Each state government, especially the Government of Kerala, can encourage local government institutions to strive for the promotion of Ayurveda centric medical tourism. This can enhance community participation.

There is a need for a proper quality control system in Ayurveda sector to address various issues in the health sector. These include legal issues which involve different countries. Ayurveda paramedical courses need special attention by improving and updating the syllabus at the Bachelor of Ayurvedic Medicine and Surgery (BAMS) level. Government of India and the respective state government should include Ayurveda sector in the formulation of policy of public health. States like Kerala have a good potential to be developed as global medical tourism destination for chronic illnesses. There is a need for setting up an independent university for Ayurveda and the creation of an Ayurvedic Research and Promotional Council.

Of late, Ayurvedic treatment has been included for medical insurance coverage in a limited way. There is an urgent need for 
policy intervention to ensure medical insurance coverage for Ayurvedic treatment with liberal terms and conditions comparable to Allopathic treatment. It is desirable to carry out regular revision of syllabi of the undergraduate/postgraduate programmes, at least once in two years. Even the Government can consider providing priority status sector to Ayurveda with adequate annual budgetary provision. Establishment of specialty hospitals and health clinics in Ayurveda with the participation of local governments and private sectors can contribute to the promotion of medical tourism on the one hand and enhance the access of cost effective public health care services to the common people on the other hand. Legal facilitation for export promotion in the area of Ayurveda can be an important step.

\section{Local Government Institutions and Community}

It is important to encourage the cultivation of new medicinal plants and develop formulations. Panchayats and Municipalities can play a bigger role in promoting cultivation of new medicinal plants. Local government institutions with the support of the respective state government can strengthen public health care ${ }^{4}$ initiatives in Ayurveda and evolve integrative health care model incorporating Ayurveda with modern medicine, homoeo, yoga and siddha. They should also take steps for the introduction of an accreditation process for hospitals and nursing, panchakarma and yoga centres. Local government can take a lead to ensure strong regulatory enforcement to prevent mushrooming of spurious drug manufacturing. Ayurveda manufacturers should be given energysaving support. Another major step required is the documentation and retrieval of traditional knowledge and research findings. Hospital waste management under Ayurvedic sector needs special attention and there is a good scope for recycling effluents.

\section{Ayurveda - Practitioners, Manufacturers and Researchers}

Fast changing scenario in the field of medical tourism calls for more basic research activities in Ayurveda with participation of scientists from modern science. It is important to conduct interdisciplinary researches for proving the efficacy of Ayurvedic medicines and treatments. Attention may be devoted to start clinical research 
initiatives with models suited for Ayurveda. Another essential step is to identify the best practices in Ayurveda and carry out documentation of the same. Standardization of about 10 classical drugs or procedures and develop protocols may be initiated.

When we talk of 'inclusive growth' in the context of Ayurveda based medical tourism, it is relevant to emphasize the dominant role of small and medium enterprises in the manufacturing of Ayurveda products. We should also highlight the contribution of practitioners and researchers in providing affordable treatments in Ayurveda sector. Moreover, the manufacturing segment of Ayurveda is comparatively labour intensive. In view of dominance of small and medium enterprises, individual researchers and practitioners and labour intensive operations, Ayurveda based medical tourism can achieve inclusive growth.

To conclude, the findings of the study provide valuable insights regarding the significance of Ayurveda sector in medical tourism. India in general and Kerala in particular is in an advantageous position to avail the opportunities in Ayurveda to project the medical tourism sector. It is vital for the local government institutions and communities should capitalize on these opportunities of Ayurveda in medical tourism. The local government can provide an ideal platform and infrastructure facilities, policy and planning procedures to maximize the benefit of Ayurveda for the local communities. The integration of Ayurvedic centric medical tourism promotion activities with the local economy along with public-private-local government partnerships can push the growth of medical tourism sector in a big way.

\section{Notes}

1. Though Ayurveda is most popular in Kerala, states like Goa and Karnataka have some presence of Ayurveda

2. Hospital Management Committee is a platform created only in Kerala though it can be compared with Rogy Kalyan Samiti in states like Bihar, Madhya Pradesh, West Bengal, etc. Hospital Management Committee is a democratically constituted body that provides a platform for elected 
representatives and officials of PRIs/ Municipalities and health officials to work jointly for the efficient functioning of public health institutions. On the contrary, Rogi Kalyan Samities are neither formed based on the democratic spirit nor developed as democratically run system.

3. Ayurveda in medical tourism is limited to massage and wellness treatments while the treatment for illness is totally neglected.

4. Public health care system does not include the network of Ayurveda hospitals and dispensaries as all the public health care related activities are being implemented through allopathic hospitals.

\section{References}

Bookman, M. Z. \& Bookman, K. R. (2007). Medical tourism in developing countries, New York: Palgrave MacMillan. Retrieved from http://utmj.org/archive/86-2/BR.pdf

Carrera, P. M. \& Bridges, J. F. P. (2006). Globalization and healthcare: understanding health and medical tourism. Expert Review Pharmacoeconomics Outcomes Research, 6 (4): 447-54. Retrieved from http://www.expert-reviews.com/doi/abs/10.1586/14737167.6.4.447

Choudhury, R., Joy, \& Dutta, R. (2004). NASSCOM-like Body to be formed for Healthcare. Express Healthcare Management.

Godwin, S. K. (2004). Medical tourism: Subsidizing the rich. Economic and Political Weekly, 39 (36), 3981-3983.

Government of India.(2002). National health policy. Ministry of Health and Family Welfare.

John, J. (2012). A study on effectiveness of Panchayati Raj institutions in health care system in the state of Kerala. Planning Commission, Government of India. Retrieved from http://planningcommission.nic.in/reports/ sereport/ser/ser_kds1803.pdf

Madhavan, H. (2009). Commercializing traditional medicine: Ayurvedic manufacturing in Kerala. Economic and Political Weekly, 44(16), 44-51. Retrieved from http://www.epw.in/authors/m-r-madhavan

Madhavan, H. (2011). Growth, transition and globalization of traditional medicine: Case of Ayurvedic pharmaceuticals in Kerala. 
Qureshi, A. S. (2001). High Level Committee for Hospitals in Delhi: Enquiry Report. New Delhi: Maulana Azad Medical College and Government of National Capital Territory of Delhi

Reddy, S., \& Qadeer, I. (2010, May 15). Medical tourism in India: Progress or predicament? Economic and Political Weekly, 45 (20). Retrieved from http:/ / www.epw.in/special-articles/medical-tourism-indiaprogress-or-predicament.html

Rollyson, S. (2010). The globalization of healthcare: A study of medical tourism. The Globalization of HealthCare, Retrieved from http:/ / globalizationhealthcare.net/wp-content/uploads/2010/ 08/GlobHC_1st_ed.pdf

United Nation. (2010), Annual report: Geneva. United Nations Conference on Trade and Development. 